\title{
Chemotherapy of Experimental Streptococcal Endocarditis
}

\author{
II. SYNERGISM BETWEEN PENICILLIN AND STREPTOMYCIN \\ AGAINST PENICILLIN-SENSITIVE STREPTOCOCCI
}

\author{
David T. Durack, Lawrence L. Pelletier, and Robert G. Petersdorf \\ From the Nuffield Department of Clinical Medicine, Radcliffe Infirmary. \\ Oxford, and Department of Medicine, University of Washington, \\ Seattle, Washington 98195
}

\begin{abstract}
A в S T R A C T Bacterial endocarditis was produced by intravenous injection of Streptococcus viridans into rabbits with preexisting sterile endocardial vegetations. After $6 \mathrm{~h}$ had elapsed, bacteria in the vegetations could not be eradicated by brief treatment with antimicrobials to which the streptococci were sensitive. However, when treatment with penicillin was continued for 4 days, the animals were cured. The 6-h infection therefore offered a model in which treatments could be conveniently compared over a short period. Synergism was demonstrated between penicillin and streptomycin in endocarditis due to a fully penicillin-sensitive streptococcus, a point which had not been previously proved in vivo. The clinical implications are discussed.
\end{abstract}

\section{INTRODUCTION}

In a previous study, we showed that streptomycin enhanced the effect of penicillin in preventing experimental Streptococcus viridans endocarditis (1). This observation was consistent with early in vitro studies by Hunter (2), who inferred from his findings that the combination might be more effective than penicillin alone in treatment of penicillin-sensitive streptococcal endocarditis. Subsequently, several clinical reports have suggested that use of both drugs may provide more effective therapy than penicillin alone (3-7). In particular, this combination may be of value in reducing the incidence of relapse after treatment (7). Despite this suggestive evidence, there is presently no agreement whether the combination of penicillin and streptomycin should be used routinely when the organisms are fully sensitive to penicillin. We have used an experimental approach in an effort to shed light on this question.

Received for publication 17 October 1972 and in revised form 19 June 1973.
Many techniques have been devised for production of bacterial endocarditis in experimental animals, but most of them are complex, and the time of onset and incidence of infection are uncertain. A more promising approach was devised by Garrison and Freedman (8) who produced bacterial endocarditis by leaving polyethylene catheters containing staphylococci in rabbits' hearts. This technique was developed further in our laboratory. Bacterial endocarditis was produced regularly in rabbits by a single intravenous injection of $S$. viridans $24-48 \mathrm{~h}$ after a sterile catheter had been placed in either side of the heart $(9,10)$. This model has been used to show that streptococcal endocarditis can be prevented by penicillin plus streptomycin, by vancomycin, or by large doses of procaine penicillin, when these drugs are administered within $0.5 \mathrm{~h}$ of intravenous injection of bacteria (1). During these experiments, we noted that if only $6 \mathrm{~h}$ were allowed to elapse before administration of the same antibiotics, infection could not be prevented (see Results). The relative refractoriness of the 6-h lesion to antimicrobial agents suggested that it might provide a useful model for evaluation of drug therapy. The present study compares the therapeutic efficacy of several antimicrobial regimens in the treatment of experimental viridans streptococcus endocarditis, with particular emphasis on the synergistic action of penicillin and streptomycin.

\section{METHODS}

Production of bacterial endocarditis. Experimental bacterial endocarditis was produced as described previously $(9,10)$. Both right- and left-sided lesions were studied; there is no significant difference between the progress of lesions on either side during the first 5 days of infection (10).

Test organism. The same strain of Streptococcus sanguis serotype II previously described $(1,9,10)$ was employed. The infecting dose was approximately $10^{8}$ colony- 
forming units given in a single injection into an ear vein. The minimal inhibitory concentration (MIC) ${ }^{1}$ and minimal bactericidal concentration (MBC) for this organism of the antibiotics employed in this study are as follows:

\begin{tabular}{|c|c|c|}
\hline & MIC & $\mathrm{MBC}$ \\
\hline Cephaloridine & $0.16 \mu \mathrm{g} / \mathrm{ml}$ & $0.16 \mu \mathrm{g} / \mathrm{ml}$ \\
\hline Erythromycin & $0.13 \mu \mathrm{g} / \mathrm{ml}$ & $0.25 \mu \mathrm{g} / \mathrm{ml}$ \\
\hline Penicillin G & $0.03 \mu \mathrm{g} / \mathrm{ml}$ & $0.03 \mu \mathrm{g} / \mathrm{ml}$ \\
\hline Streptomycin & $8.0 \mu \mathrm{g} / \mathrm{ml}$ & $8.0 \mu \mathrm{g} / \mathrm{ml}$ \\
\hline Tetracycline & $0.20 \mu \mathrm{g} / \mathrm{ml}$ & - \\
\hline Vancomycin & $0.62 \mu \mathrm{g} / \mathrm{ml}$ & $0.62 \mu \mathrm{g} / \mathrm{ml}$ \\
\hline
\end{tabular}

Administration of antibiotics. Standard commercial preparations of the various antimicrobials were given intramuscularly or intravenously in the doses and at the times detailed in the section on Results. For intravenous infusion, the animal was held in a restraining cage, a plastic cannula was passed into an ear vein, and the solution was infused at a rate of $1-2 \mathrm{ml} / \mathrm{h}$.

Serum levels. To measure the level of antimicrobial activity in serum after administration of antibiotics, blood was drawn from the ear vein and allowed to clot. Serial twofold dilutions of serum were made in glucose broth, and approximately $10^{4}$ colony-forming units of the test strain of streptococcus were added to $1 \mathrm{ml}$ of each dilution. The highest dilution failing to show visible growth after 18 $h$ at $37^{\circ} \mathrm{C}$ was taken as the MIC. The MBC for each drug was determined by culturing a loopful from each clear tube on blood agar. The highest dilution showing no growth was taken as the end point.

Bacterial killing. An overnight broth culture of Streptococcus sanguis (serotype II) was diluted in TSY broth to make a final concentration of $10^{5}$ and $10^{2}$ organisms, respectively. $1 \mathrm{ml}$ of each was added to a series of $16 \times$ 150-mm screw-capped tubes containing TSY broth; $1 \mathrm{ml}$ containing $10^{5}$ bacteria was added to pooled rabbit serum instead of TSY broth. The tubes were placed on a Fisher rotating rack (Fisher Scientific Co., Pittsburgh, Pa.) at $37^{\circ} \mathrm{C}$ and were rotated for $6 \mathrm{~h}$ to simulate growth on the heart valve in vivo. At that time, samples to determine bacterial counts were taken and then $1 \mathrm{ml}$ of penicillin $(1.0 \mu \mathrm{g} / \mathrm{ml})$, streptomycin $(32 \mu \mathrm{g} / \mathrm{ml})$, and the combination was added to each tube to give a final volume of 10 $\mathrm{ml}$; one set of tubes was left without antibiotic. All the tubes were then replaced on the rotating rack and sampled at $6,9,12$, and $18 \mathrm{~h}$ after the addition of antibiotics. Bacterial counts were determined by routine plate dilution after $24-48 \mathrm{~h}$ of incubation at $37^{\circ} \mathrm{C}$. Penicillinase was added to all plates of aliquots taken from tubes containing penicillin.

Evaluation of infection. Rabbits were killed from 1 to 5 days after injection of streptococci, at least $12 \mathrm{~h}$ after the last dose of antibiotic. The hearts were removed with antiseptic precautions and dipped briefly into boiling water to eliminate contaminants. The chambers of the heart were opened, the vegetations were excised, weighed, homogenized in glass tissue grinders, and suspended in glucose broth. The number of colony-forming units per gram of vegetation was determined by counting colonies after incorporating serial dilutions of the homogenate into blood agar pour plates and incubating at $37^{\circ} \mathrm{C}$. The volume of

${ }^{1}$ Abbreviations used in this paper: $\mathrm{MBC}$, minimal bactericidal concentration; MIC, minimal inhibitory concentration. agar used was such that the final dilution of the homogenized vegetation was never less than $500: 1$, thus diluting any antibiotic contained in the vegetation below an effective concentration. Penicillinase was added to each culture plate when penicillin had been used.

\section{RESULTS}

Infection of $6 h$ duration as a test systcm. Bacterial endocarditis was prevented in all of 9 rabbits given procaine penicillin $\mathrm{G} 250 \mathrm{mg} / \mathrm{kg}$ intramuscularly and all of 11 given vancomycin $30 \mathrm{mg} / \mathrm{kg}$ intravenously within $30 \mathrm{~min}$ of injection of bacteria (1). However, when administration of these drugs was delayed for $6 \mathrm{~h}$, the treatment failed in all of 9 animals treated with procaine penicillin $G$ and 11 of 14 treated with vancomycin.

Failure of constant infusion of antibiotics. We had shown previously that most of the antibiotics which failed to prevent experimental endocarditis were active for less than $6 \mathrm{~h}$ in rabbit blood when given in single doses (1). It seemed likely that rapid excretion of the drugs was a factor in treatment failure. 12 animals were therefore treated with benzyl-penicillin $G$, vancomycin, tetracycline, or erythromycin by constant infusion for 9 h. Serum activity was monitored during the period of the infusion; the serum always inhibited growth of the organism at dilutions of $1: 8$ to $1: 128$. Despite constant exposure of the infected vegetation to blood of effective antimicrobial activity for $9 \mathrm{~h}$, all 12 animals were heavily infected at $24 \mathrm{~h}$.

Effect of prolonged treatment. The high incidence of failure with all the drugs tested seemed in accord with clinical experience that prolonged therapy is required to cure bacterial endocarditis. To evaluate more prolonged treatment, it was necessary to compare results with the course of infection in untreated controls, because a small proportion of spontaneous cures may be encountered in right-sided experimental endocarditis (10). No cures were achieved in 15 animals treated with procaine penicillin $\mathrm{G} 250 \mathrm{mg} / \mathrm{kg}$ daily for 1 or 2 days. Of six animals treated for 3 days, two were found to have sterile lesions, but one of eight controls was also free of infection, All 9 animals treated for 4 or 5 days were cured, while all 10 controls in that experiment remained infected (Table I).

\section{Synergism between penicillin and streptomycin}

In vitro observations. In a previous study (1), we had demonstrated by means of an in vitro killing curve, apparent synergism between penicillin and streptomycin against $S$. sanguis. In that study, organisms that were incubated with penicillin alone persisted in the medium after $24 \mathrm{~h}$, while the combination of penicillin and streptomycin killed all of the bacteria. In the present study. it was difficult to demonstrate synergism with the usual serum bactericidal test (Fig. 1) and there appeared to be 
TABLE I

Treatment with Procaine Penicillin for 5 Days, Starting at $6 h$ : Right-sided endocarditis

\begin{tabular}{rccc}
\hline & \multicolumn{2}{c}{ No. infected/no. animals } \\
\cline { 2 - 4 } & $\begin{array}{c}\text { Procaine } \\
\text { penicillin, } \\
250 \mathrm{mg} / \mathrm{kg} \\
\text { daily }\end{array}$ & \\
& Cntreated value* \\
\hline For 1 day & $6 / 6$ & $9 / 9$ & $\mathrm{NS}$ \\
2 days & $2 / 2$ & $6 / 6$ & $\mathrm{NS}$ \\
3 days & $7 / 8$ & $4 / 6$ & $\mathrm{NS}$ \\
4 days & $5 / 5$ & $0 / 5$ & $<0.005$ \\
5 days & $5 / 5$ & $0 / 4$ & $<0.01$ \\
\hline
\end{tabular}

* Fisher's exact test.

no difference between penicillin and the combination of penicillin and streptomycin, suggesting that the antibacterial activity was due to penicillin alone. However, there was clear-cut enhancement of penicillin's antibacterial activity by streptomycin when the rate of bacterial killing was measured. An inoculum of $10^{5} S$. sanguis was permitted to grow in broth for $6 \mathrm{~h}$ at which time penicillin, streptomycin, and the combination of drugs, in concentrations of 1.0 and $32 \mu \mathrm{g}$, respectively for penicillin and streptomycin were added to the incubation mixture. $9 \mathrm{~h}$ later, penicillin and streptomycin alone had achieved only modest bacterial killing, while the combination had eradicated all of the organisms. Two additional features of this experiment are of interest: $(a)$ When a low inoculum $\left(10^{2}\right)$ of $S$. sanguis was employed, a synergistic effect between penicillin and streptomycin was not identifiable, and penicillin alone killed the organisms as rapidly as did both drugs. This result is not surprising because many antimicrobials seem more potent with low inocula than when exposed to a higher concentration of organisms. More pertinent to these studies is the fact that the inoculum size at which synergism was demonstrated is close to the number of organisms found in infected heart valves in this model. (b) Although streptomycin alone exerted some antibacterial activity initially, after $6 \mathrm{~h}$ of incubation multiplication occurred in the presence of the drug. (c) Although not shown in Fig. 2, substitution of serum for broth did not alter the results.

In Vivo studies. Streptococci were injected intravenously into a total of 59 rabbits with aortic catheters. After $6 \mathrm{~h}$ had elapsed treatment was begun with procaine penicillin G $25 \mathrm{mg} / \mathrm{kg}$, streptomycin $15 \mathrm{mg} / \mathrm{kg}$, or both. The drugs were given intramuscularly at $12-\mathrm{h}$ intervals, in doses which were chosen to approximate on a weight basis those which might be used in man. One group of rabbits was left untreated. Mean serum bactericidal levels on duplicate tesț in three rabbits receiving these regimens are illustrated in Fig. 1. Streptomycin

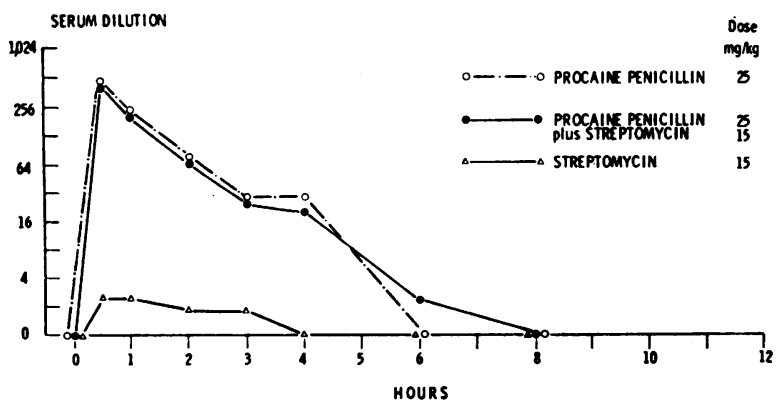

Figure 1 Highest dilution of serum which was bactericidal for the test strain of streptococcus after administration of procaine penicillin G, streptomycin, or both.

gave only low and transient bactericidal levels, consistent with its $\mathrm{MBC}$ of $8.0 \mu \mathrm{g} / \mathrm{ml}$. The serum was bactericidal in high dilution after intramuscular procaine penicillin $\mathrm{G}$, with 6-8-h duration of activity. The bactericidal activity of serum after procaine penicillin $G$ was not significantly increased or prolonged by the addition of streptomycin.

Animals were sacrificed after 1,2 , or 3 days of therapy and vegetations were cultured quantitatively. Fig. 3 depicts the results of treatment. Vegetations of all untreated animals contained high counts of streptococci. During the 3-day period of the experiment both penicillin and streptomycin alone reduced the counts significantly $(P<0.05$, Fisher exact test $)$ and the combination was superior to either drug used alone $(P<0.05)$. Most importantly, total sterilization was achieved in all six rabbits treated with the combination for 3 days. This contrasted with the partial bactericidal action of either drug alone.

The results of this experiment suggested that the majority of bacterial killing occurred in the first $24 \mathrm{~h}$ after administration of antibiotic. For this reason, a

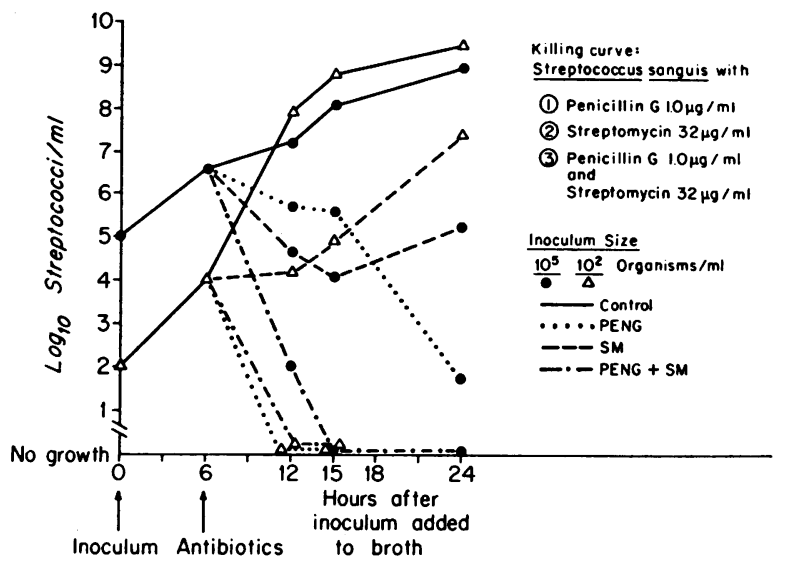

FIgURE 2 Rate of bacterial killing of $10^{5}$ and $10^{2} / \mathrm{ml} S$. sanguis after exposure to penicillin, streptomycin, or a combination of the two drugs. 


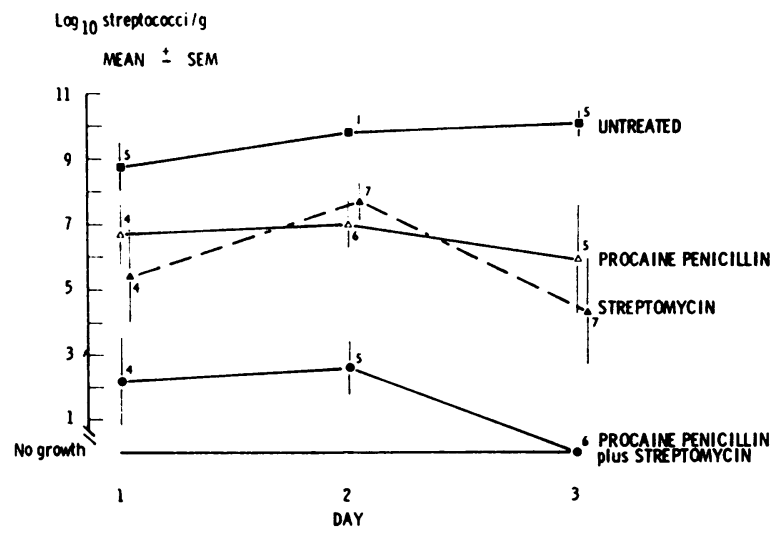

Figure 3 Mean \pm SEM $\log _{10}$ colony-forming units of streptococci per gram vegetation in untreated rabbits, and rabbits given procine penicillin G, streptomycin, or both, followed for a 3-day period. Number of animals used is shown at each point.

second experiment was performed in which the animals were handled as in the above experiment except that animals in each group were sacrificed 12 and $24 \mathrm{~h}$ after onset of treatment (18 and $30 \mathrm{~h}$ after injection of bacteria). The results are depicted in Fig. 4. There was some bacterial killing by penicillin, streptomycin, and the combination during the first $12 \mathrm{~h}$ after administration of the drug; $12 \mathrm{~h}$ later there were still a large number of bacterial on the heart valves of animals treated with penicillin alone, while all eight animals treated with the combination had sterile vegetations. The difference between the penicillin and streptomycin group and those groups treated with either drug alone was highly significant $(P<0.05)$.

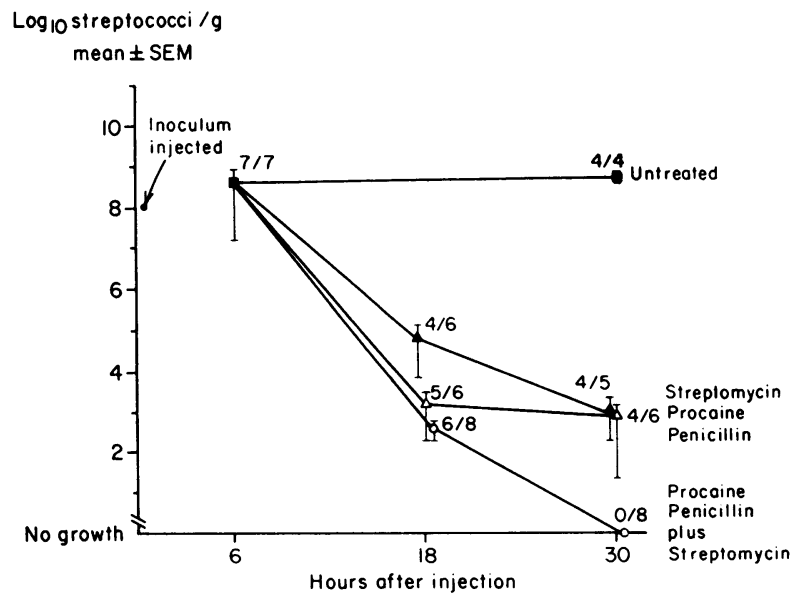

Figure 4 Mean \pm SEM $\log _{10}$ colony-forming units of $S$. sanguis per gram vegetation 12 and $24 \mathrm{~h}$ after treatment with penicillin $G$, streptomycin, or a combination of the drugs. Number of animals is shown at each point.

\section{DISCUSSION}

These experiments demonstrated a striking change in response to chemotherapy when bacteria which had localized on sterile endocardial vegetations were allowed $6 \mathrm{~h}$ of unimpeded growth. Therapy capable of eliminating infection $30 \mathrm{~min}$ after intravenous injection of bacteria nearly always failed if administration was delayed for $6 \mathrm{~h}$. The reason for this difference cannot be stated with certainty, but multiplication of bacteria and the total number present in the vegetation at any one time are undoubtedly significant factors. Our previous studies showed that the organisms originally lodged on the valve increased by approximately 1,000 -fold during this 6-h period (9). It is likely, therefore, that the population of organisms in the vegetation at $6 \mathrm{~h}$ had become too large for complete eradication by a single dose of any antibiotic. It is also conceivable that a proportion of the bacteria had already entered a resting phase and would be less susceptible to most antibiotics, especially those drugs which affect cell-wall synthesis. The virtual absence of phagocytes in the vegetation must also play an important role in persistence of bacteria. Cure of the infection was achieved when penicillin treatment was continued for 4 or 5 days.

Whatever the reasons for the refractoriness of the 6-h infection, it has proved to be a reproducible model in which various antimicrobial regimens can be tested in vivo. The time scale appears to be telescoped so that therapy takes effect over a shorter period than in human endocarditis. Relative efficacy of various regimens can be evaluated under controlled conditions in vivo in as little as 3-5 days.

When the efficacy of penicillin and streptomycin alone and in combination against a fully penicillin-sensitive streptococcus was tested in the 6-h treatment model, the combination was strikingly superior to either drug alone. Although the rate of killing by this combination differed somewhat in the two sets of experiments reported (Figs. 2 and 4), in both instances, the rate of bacterial killing and, more importantly, the sterilization of the vegetation was more rapid with the combination of penicillin and streptomycin than with penicillin alone. The question arises whether this may properly be termed "synergism." Early definitions of synergism held that synergism conoted an inhibitory effect from two drugs at concentrations lower than could be accounted for by mere summation (11). However, interpretation of findings such as those shown in Figs. 2 and 4 raises the practical difficulty of deciding whether the results represent synergism or merely summation. This problem is more semantic than pragmatic if the definition for synergism suggested by Garrod and O'Grady in 1971 is employed. "Whatever definition of synergy may be preferred, an effect so different as total sterilization from the partial bac- 
tericidal action of the two components must surely deserve this description" (12). We feel that the total sterilization following the use of both drugs in these experiments is acceptable as true synergism. Moreover, to our knowledge, this is the first in vivo demonstration of penicillin-streptomycin synergism against a strain of viridans streptococcus fully sensitive to penicillin. The results emphasize that in vitro measurements, such as serum bactericidal levels (Fig. 1) are not always adequate in planning therapy for endocarditis. On the other hand, a more sophisticated in vitro test such as a bacterial killing curve, will measure synergism between drugs, when ordinary sensitivity tests on antibacterial activity of serum will fail to do so.

It is of interest that streptomycin alone exerted substantial bactericidal activity against the $S$. viridans used in the model. This finding is consistent with early reports of occasional cures with streptomycin in patients (13), and is in keeping with its rapid bactericidal effect (14). Nevertheless, streptomycin is unsuitable as the sole agent for treatment of bacterial endocarditis because of the likelihood that drug-resistant strains will develop.

In assessing the relevance of these findings to clinical practice, the possible advantage of combination therapy must be weighed against the potential toxicity of streptomycin and the generally good results obtained with penicillin alone. Favorable results after only 2 wk of treatment with either penicillin alone or combined therapy in sensitive streptococcal endocarditis have been reported recently (7). However, it is noteworthy that the only two relapses that occurred took place among the 13 patients who received penicillin alone, while no relapses occurred among 36 patients who received both penicillin and streptomycin.

We therefore present this experimental evidence in support of combined therapy with both penicillin and streptomycin in penicillin-sensitive streptococcal endocarditis in man. The reasons for this conclusion are: in vitro evidence of enhanced activity against some strains (2) ; suggestive clinical observations cited previously $(3,4,5,6,7)$; evidence that the penicillin-streptomycin combination is superior in prophylaxis of experimental $S$. viridans endocarditis (1); and the findings in the present study of treatment. If the danger of increased toxicity due to impaired renal function or advanced age is given due consideration, the addition of streptomycin to penicillin should confer a worthwhile therapeutic advantage. In particular now that 2-wk treatment schedules are being used more commonly, this combination may minimize the incidence of relapse after shortterm treatment.

\section{ACKNOWLEDGMENTS}

We are indebted to Professor Paul B. Beeson for helpful advice and criticism and to Miss Kathy Nielson for her expert technical assistance.

\section{REFERENCES}

1. Durack, D. T., and R. G. Petersdorf. 1973. Chemotherapy of experimental streptococcal endocarditis. I. Comparison of commonly recommended prophylactic regimens. J. Clin. Invest. 52: 592.

2. Hunter, T. H. 1952. The treatment of some bacterial infections of the heart and pericardium. Bull. N. Y. Acad. Med. 28: 213.

3. Hall, B., H. F. Dowling, and W. Kellow. 1955. Successful short-term therapy of streptococcal endocarditis with penicillin and streptomycin. Am. J. Med. Sci. 230: 73.

4. Hunter, T. H., and P. Y. Paterson. 1956. Bacterial endocarditis. Disease-a-Month 2(November).

5. Geraci, J. E. 1958. The antibiotic therapy of bacterial endocarditis. Med. Clin. North Am. 42: 1101.

6. Tompsett, R. 1964. Diagnosis and treatment of bacterial endocarditis. Disease-a-Month. 10 (September).

7. Tan, J. S., C. A. Terhune, Jr., S. Kaplan, and M. Hamburger. 1971. Successful two-week treatment schedule for penicillin-susceptible streptococcus viridans endocarditis. Lancet. 2 : 1340.

8. Garrison, P. K., and L. R. Freedman. 1970. Experimental endocarditis I. Staphylococcal endocarditis in rabbits resulting from placement of a polyethylene catheter in the right side of the heart. Yale J. Biol. Med. $42: 394$.

9. Durack, D. T., and P. B. Beeson. 1972. Experimental bacterial endocarditis I. Colonization of a sterile vegetation. Br. J. Exp. Pathol. $53: 44$.

10. Durack, D. T., P. B. Beeson, and R. G. Petersdorf. 1973. Experimental bacterial endocarditis. III. Production and progress of the disease in rabbits. Br. J. Exp. Pathol. 54 : 142.

11. Thatcher, F. S. 1949. Synergism between antibacterial substances with special reference to streptomycin. In Streptomycin, S. A. Waksman, editor. Williams \& Wilkins Co., Baltimore. 219.

12. Garrod, L. P., and F. O'Grady. 1971. Antibiotic and chemotherapy. Williams \& Wilkins Co., Baltimore. 3rd edition. 273.

13. Hunter, T. H. 1947. Use of streptomycin in the treatment of bacterial endocarditis. Am. J. Med. 2: 436.

14. Garrod, L. P. 1948. The bactericidal action of streptomycin. Br. Med. J. 1: 382. 